\title{
Detecting Data Errors in Organizational Settings: Examining the Generalizability of Experimental Findings
}

\author{
Barbara D. Klein \\ University of Michigan-Dearborn \\ bdklein@umd.umich.edu
}

\begin{abstract}
Experiments show that giving users incentives helps them detect errors in data and that expectations about the base rate of errors in data improve error detection. However, experimental findings are often criticized as not being generalizable to organizational settings. The study reported here examines the generalizability of experimental findings on user detection of data errors. A field interview study was conducted to examine this question. Twenty interviews were conducted with users of information systems in a variety of organizational settings. The findings of the field interview study show that strong informal incentives, perceptions about the materiality of data errors, and perceptions about the base rate of errors in data affect the detection of data errors in organizational settings.
\end{abstract}

Keywords: information quality, data quality, error detection, data errors

\section{Introduction}

There is a growing recognition of the importance of managing information (Davenport, 1997), and managers are increasingly recognizing the importance of information quality (Huang et al., 1999). Several studies show that data stored in organizational databases have a significant rate of errors (e.g., Laudon, 1986; Madnick and Wang, 1992; Morey, 1982; Redman, 1992). Recent developments in information systems such as enterprise resource systems (Escalle and Cotteleer, 1999; Robinson and Dilts, 1999) and data warehousing (Ferdinandi, 1999) have increased the need to eliminate errors in data. If efforts to eliminate data errors are unsuccessful, the organizational price in terms of poor support of business processes and decision making is likely to be high (Redman, 1995).

Two approaches to eliminating errors in data are (1) validating data as they are input to or stored in databases and (2)

Material published as part of this journal, either on-line or in print, is copyrighted by the publisher of Informing Science. Permission to make digital or paper copy of part or all of these works for personal or classroom use is granted without fee provided that the copies are not made or distributed for profit or commercial advantage AND that copies 1) bear this notice in full and 2) give the full citation on the first page. It is permissible to abstract these works so long as credit is given. To copy in all other cases or to republish or to post on a server or to redistribute to lists requires specific permission and payment of a fee. Contact Editor@inform.nu to request redistribution permission. depending on users to detect and correct errors. Two laboratory experiments examining the efficacy of the second approach have been completed. Experiments show that giving users incentives helps them detect errors in data and that expectations about the base rate of errors in data improve error detection.

The findings provide the foundation for organizational initiatives designed to improve error detection. However, experimental findings are often criticized as not being generalizable to organizational settings (Fromkin and Streufert, 1976). This paper discusses the results of a field interview study conducted to link the findings of laboratory experiments on user detection of data errors to practice in organizations. Twenty interviews were conducted with professionals in four business domains in order to increase our understanding of the applicability of the laboratory findings to organizational practices.

The remaining sections of this paper present (1) a review of prior research bearing directly on the question of the conditions under which individuals detect errors in data, (2) a discussion of the theoretical framework underlying the study and the propositions tested in the study, (3) the results of the prior laboratory experiments on user detection of data errors (4) the design of the field interview study, (5) the results of the field interview study, and (6) conclusions and suggestions for further research. 


\section{Background}

The relevant research on data quality can be summarized with several conclusions. First, there is agreement that data accuracy, currency, and completeness are important aspects of data quality (Agmon and Ahituv, 1987; Davis and Olson, 1985; Fox et al., 1993; Huh et al., 1990; Madnick and Wang, 1992; Wand and Wang, 1994; Zmud, 1978). Second, error rates significantly greater than zero have been found in all of the studies addressing the extent to which data errors exist in databases (Ham et al., 1985; Johnson et al., 1981; Knight, 1992; Laudon, 1986; Stone and Bublitz, 1984). Third, while some researchers have proposed methods designed to completely rid databases of errors (Janson, 1988; Svanks, 1988; Naus, 1975; Parsaye and Chignell, 1993), others propose tools for determining how to best allocate limited resources to controlling the level of data errors (Ballou and Pazer, 1987; Ballou and Tayi, 1989; Ballou et al., 1987; Bowen, 1992; Paradice and Fuerst, 1991). Fourth, a variety of approaches for using imperfect data have been suggested (Ballou and Pazer, 1985; Ballou and Pazer, 1995; Ballou and Pazer, 1987; Bansal, 1993; Gaba and Winkler, 1992; Garfinkel et al., 1986; O’Leary, 1993; O'Neill and VizineGoetz, 1988).

The early literature on data quality argues that users are not very capable of finding data errors and then changing the way that they use the data. Several studies found evidence of poor performance in detecting data errors. Davis et al. (1967) conducted a field experiment in which approximately half the subjects failed to detect important errors in a banking statement. Laudon (1986) found that users of criminal information systems rarely detected errors in these records. Ricketts (1990) conducted a laboratory experiment in which over ninety percent of the subjects failed to detect a substantial data error in production planning reports. The failure of users to detect errors in data is also assumed in the literature on data quality that argues that resources should be devoted to the up-front improvement of data quality (e.g., Redman, 1992; Redman, 1995).

In contrast to the findings of the early studies, Klein (1997) found that all of the actuaries interviewed in a field study reported instances in which they successfully detected errors in data. The degree to which data items were reviewed for errors prior to use was affected by the actuaries' expectations about the likelihood of errors in a given dataset. The actuaries did not attempt to detect all errors, apparently responding to a perceived tradeoff between the time and effort required to find additional errors versus the potential impact of a more accurate dataset.
More recent laboratory experiments show that people detect data errors under some conditions. Specifically, incentives and expectations about the base rate of errors in data have been linked to performance in the detection of data errors (Klein et al., 1997; Klein, 1999).

\section{Theoretical Framework and Propositions}

The research model underlying this study is presented in Figure 1. Model constructs and the research propositions are discussed below.

Error detection performance is viewed here as the successful or unsuccessful detection of an error in data. We argue here that differences in expectations about the base rate of errors in data and assessments of the payoffs of error detection affect the rate at which errors are detected through choices related to effort.

Campbell's (1990) theory of performance argues that choices about the degree of effort to expend in a task will influence performance. Klein's (1997) study of actuaries and the detection of data errors suggests that there are several factors that influence these choices when users work with imperfect data. Factors influencing choices related to effort in error detection are discussed below.

\section{Payoffs of Error Detection}

Formal and informal incentives, perceptions about the materiality of data errors, and perceptions about the ease of verifying and correcting suspected data errors may affect users' assessments of the payoffs of error detection.

\section{Incentives}

Incentives may affect users' assessments of the payoffs of error detection. Both formal incentives, such as increases in salary, bonuses, and formal recognition, as well as informal incentives, such as indirect links to progress in the organization, indirect links to pay increases, and informal recognition, may affect error detection.

\section{Proposition 1: Formal incentives will positively affect error detection performance.}

\section{Proposition 2: Informal incentives will positively affect error detection performance.}




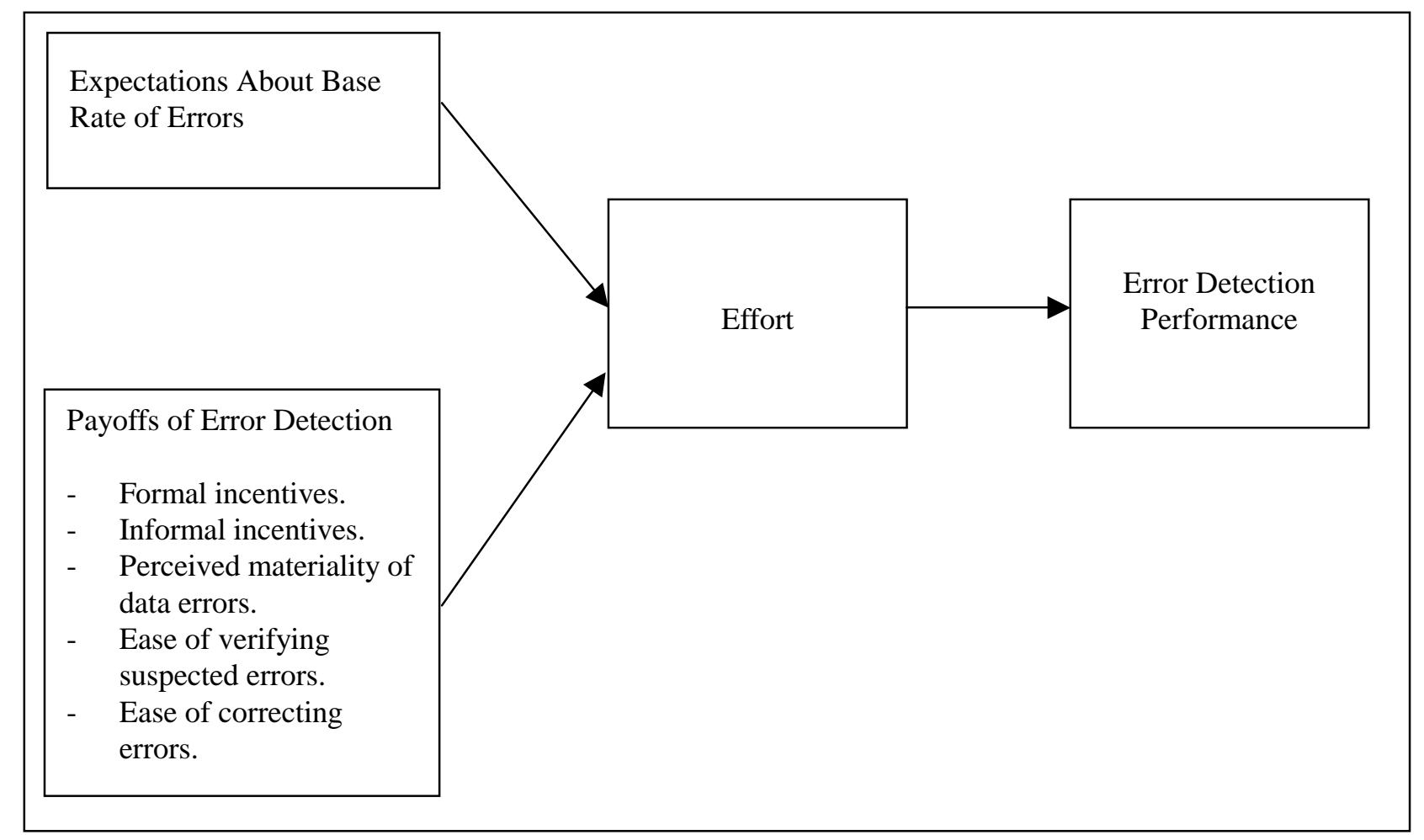

Figure 1. Research Model

\section{Materiality}

The degree of effort expended to detect a data error may be affected by beliefs about the materiality of errors. For example, users may expend more effort to detect errors that they believe will have a significant impact on their work. There is evidence from the study of the actuaries that the impact of data errors on the work being performed using data is explicitly considered in the determination of the level of effort to expend in error detection. For example, one actuary stated that there are some types of errors that he does not try to detect when pricing insurance because the errors would not have a significant impact on his calculations.

\section{Proposition 3. Perceptions about the materiality of data errors will positively affect error detection per- formance.}

\section{Ease of Verification and Correction}

The degree of effort expended to detect an error may also be affected by the ease with which an error can be verified and corrected. For example, individuals may not try very hard to detect an error if it is difficult to confirm that a suspected error is actually an error or if it is not possible to correct a confirmed error.
Proposition 4: Perceptions about the ease of verifying suspected data errors will positively affect error detection performance.

Proposition 5: Perceptions about the ease of correcting data errors will positively affect error detection performance.

\section{Expectations about the Base Rate of Errors in Data}

Greater effort may be devoted to error detection if users expect more errors in data. The study of the actuaries suggests that expectations about the base rate of errors in a source of data influence the effort devoted to error detection. For example, one actuary reported that she does not attempt to find errors in published mortality tables because she considers the base rate of errors in the tables to be low (Klein, 1997).

Proposition 6: Perceptions about the base rate of errors will positively affect error detection performance.

\section{Prior Experimental Findings Based on the Theoretical Framework}

Two laboratory experiments based on this theoretical framework have been conducted. Both experiments tested the effect of formal incentives and expectations about the base rate of errors on error detection. Other constructs in the research model were not tested in the experiments. 


\section{Experiment 1}

The operationalization of the research constructs and the experimental findings for the first experiment are summarized below. The complete details of the experiment are available in Klein et al. (1997).

\section{Operationalization of Incentives and Expectations about the Base Rate of Errors}

216 students taking upper-level and graduate business courses participated in the experiment. Subjects in the experiment were required to calculate pensions for the employees of a set of clients and to note data errors on confirmation memos to be sent to the clients. The incentive construct was operationalized through a lottery that gave subjects a 1 in 18 chance of winning a $\$ 100$ prize. Four conditions were tested: Detection, Pension Calculation, Detection with False Alarm Penalty, and Control. In the Detection and Detection with False Alarm Penalty conditions, subjects were told that their performance on the task would be evaluated (with performance on the confirmation memos weighted three times as heavily as performance on the accrued pension calculations) and that the thirty percent of subjects with the best performance would be entered into a lottery from which one person would receive $\$ 100$. Subjects in the Detection with False Alarm Penalty condition were told that the number of errors noted and the amount of unnecessary costs incurred by the client would be considered in the evaluation of the quality of their confirmation memos. Subjects in the Pension Calculation condition were told that their performance on the task would be evaluated (with performance on the accrued pension calculations weighted three times as heavily as performance on the confirmation memos) and that the thirty percent of subjects with the best performance would be entered into a lottery from which one person would receive $\$ 100$. The $\$ 100$ prizes were not contingent on task performance in the Control condition.

The expectations about the base rate of errors construct was operationalized by giving subjects information about the error rate of data provided by the clients in the past. Three conditions were tested: High, Low, and Control. In the high base rate condition, a memo stated that the clients for whom the subjects would be performing the accrued pension calculation task tend to provide data containing a lot of errors. In the low base rate condition, a memo stated that the clients for whom the subjects would be performing the accrued pension calculation task tend to provide data mostly free of errors. No mention of the accuracy of the data provided by the clients in the past is made in a memo read by subjects in the control condition.

\section{Results of Experiment 1}

The expectations about the base rate of errors factor did not affect the number of data errors found, but the incentive factor did ( $p=.0001)$. Subjects could find a maximum of 36 data errors. Table 1 shows the number of errors detected and the detection rate for each of the four levels of the incentive factor.

\begin{tabular}{|l|l|}
\cline { 2 - 2 } \multicolumn{1}{l|}{} & $\begin{array}{l}\text { Error Detection } \\
\text { Performance }^{1}\end{array}$ \\
\hline Detection & $20.0(.56)$ \\
\hline Pension Calculation & $16.0(.44)$ \\
\hline $\begin{array}{l}\text { Detection with False } \\
\text { Alarm Penalty }\end{array}$ & $13.8(.38)$ \\
\hline Control & $12.2(.34)$ \\
\hline
\end{tabular}

${ }^{1}$ Each cell in this column gives the mean number of errors detected followed by the detection rate in parentheses.

\section{Table 1. Error Detection Performance in Experiment 1}

Using the Tukey method of multiple comparisons with a family confidence coefficient of .95 , it was concluded that: (1) subjects in the Detection condition found significantly more data errors than subject in the other three conditions and (2) subjects in the Pension Calculation condition found significantly more data errors than subjects in the Control condition.

\section{Experiment 2}

The operationalization of the research constructs and the experimental findings for the second experiment are summarized below. The complete details of the experiment are available in Klein (1999).

\section{Operationalization of Incentives and Expectations about the Base Rate of Errors}

The incentive factor was operationalized as in Experiment 1. Three levels were tested: Detection, Control, and No Incentive. The Detection and Control conditions from Experiment 1 were used in this experiment. A third level with no possibility of winning a prize was added (No Incentive).

The expectations about the base rate of errors construct was operationalized through direct experience. Three levels were tested: High, Low, and Control. In the High base rate 
condition, subjects performed the pension calculations using a dataset containing an error rate of 30 percent before performing the pension calculations for a second target division. In the Low base rate condition, subjects performed the pension calculations using a dataset containing an error rate of four percent before performing the pension calculations for a second target division. In the Control condition subjects had no prior experience from which to develop base rate expectations before performing the pension calculations for the target division. The error rate for the target division was the same ( 10 of the 50 records contained an error) for all the experimental conditions.

\section{Results of Experiment 2}

The incentive factor and the expectations about the base rate of errors factor both affected the number of errors detected in the target division ( $\mathrm{p}=.0001$ for both factors). Subjects could find a maximum of 10 data errors in the target division. Table 2 shows the number of errors detected and the detection rate for each of the four levels of the incentive factor and the three levels of the expectations about the base rate of errors factor.

\begin{tabular}{|c|c|c|c|c|}
\hline & & \multicolumn{3}{|c|}{ Base Rate Expectations } \\
\hline & & High & Control & Low \\
\hline \multirow[b]{3}{*}{$\Xi$} & Detection & $7.5(.75)$ & $5.6(.56)$ & $3.4(.34)$ \\
\hline & Control & $5.1(.51)$ & $3.4(.34)$ & $3.0(.30)$ \\
\hline & $\begin{array}{l}\text { No } \\
\text { Incentive }\end{array}$ & $3.9(.39)$ & $3.3(.33)$ & $2.4(.24)$ \\
\hline
\end{tabular}

Each cell gives the mean number of errors detected followed by the detection rate in parentheses.

\section{Table 2. Error Detection Performance in Experiment 2.}

Using a family confidence coefficient of .95 for the incentives factor, it was concluded that subjects in the Detection condition found more data errors than subjects in the Random condition and that subjects in the Detection condition found more data errors than subjects in the No Incentive condition. The following conclusions were drawn for the base rate expectations factor using a family confidence coefficient of .95: (1) subjects in the High condition found more data errors than subjects in the Control condition, (2) subjects in the High condition found more data errors than subjects in the Low condition, and (3) subjects in the Control condition found more data errors than subjects in the Low condition.

\section{Design of the Field Interview Study}

A field interview study was conducted to examine the generalizability of the experimental findings to organizational settings. Rather than focusing exclusively on incentives and expectations about the base rate of errors, the field interview study examines payoffs of error detection more broadly by examining the effects of formal incentives, informal incentives, perceptions about the materiality of data errors, and perceptions about the ease of verifying and correcting data errors on the detection of data errors.

Interviews were conducted in four professional domains: (1) consumer product management, (2) inventory management, (3) municipal bond analysis, and (4) actuarial science. None of the actuaries interviewed in the initial study of actuaries and error detection were interviewed in this study. Instead, new participants were recruited. Interviews were conducted in the four different professional domains to make it more likely that we would interview users with a broad spectrum of perceptions about the research constructs. The choice of domains follows the advice of Eisenhardt (1989) and Yin (1989) with respect to the selection of theoretically interesting cases.

Five professionals were selected from each of the four professional domains. To control for selection bias, potential interviewees were asked to participate in a study of the use of data in their work. The terms "error detection" and "data quality" were not used when recruiting subjects. Data were collected using a semi-structured interview. Several of the questions in the interview protocol are a variation on the critical incidents methodology developed by Flanagan (1954). These questions were designed to elicit descriptions of incidents in which the interviewees successfully detected errors in data.

The semi-structured interviews were recorded and transcribed. An analysis of the interview transcripts was performed using methodologies outlined by Miles and Huberman (1994) and King (1994). A coding scheme based on the theoretical framework was developed, and the transcripts were coded using this scheme.

Two researchers independently coded four of the interview transcripts. Overall, the level of agreement was 94 percent. The two coders were in complete agreement about the presence or absence of evidence reflecting incidents of error detection. One coder scored the remaining eighteen transcripts. 


\section{Results}

Each of the twenty interviewees was classified as either reporting an incident in which a data error was detected or not reporting an incident in which a data error was detected. An example of an error detection incident described by one of the interviewees is available in Appendix A. The classification for each interviewee is shown in the third column of the table in Appendix B

Results for the effects of users' perceptions about the payoffs of error detection and expectations about the base rate of errors in data will be discussed in turn.

\section{Payoffs and Error Detection}

Perceptions about the payoffs of error detection are divided into five categories: (1) formal incentives, (2) informal incentives, (3) perceptions about the materiality of data errors, (4) perceptions about the ease of verifying suspected data errors, and (5) perceptions about the ease of correcting data errors. Each interviewee was assigned a judgment of High, Moderate, or Low for each of these five categories when the interview transcripts were coded. The judgements for each of the interviewees are shown in the fourth, fifth, sixth, seventh, and eighth columns of the table in Appendix B.

\section{Formal Incentives.}

Table 3 shows the number of interviewees judged to have High, Moderate, and Low formal incentives to detect errors who did and did not report detecting data errors. Notice that none of the interviewees who did not report error detection incidents reported that strong or moderate formal incentives to detect data errors exist in their organizations. In contrast, five of the interviewees who did report error detection incidents also reported strong or moderate formal incentives to detect data errors.

Even so, a chi-square test does not support the hypothesis that there is a relationship between formal incentives and error detection at a level of significance of $.05\left(\chi_{2}^{2}=2.85 ; p>.10\right)$, possibly because of a small sample size.

\begin{tabular}{|l|l|l|l|}
\cline { 2 - 4 } \multicolumn{1}{c|}{} & \multicolumn{3}{c|}{ Formal Incentives } \\
\hline Performance & High & Moderate & Low \\
\hline Error Detected & 1 & 4 & 9 \\
\hline $\begin{array}{l}\text { Error Not } \\
\text { Detected }\end{array}$ & 0 & 0 & 6 \\
\hline
\end{tabular}

Table 3. Relationship Between Formal Incentives and Performance

\section{Informal Incentives.}

Table 4 shows the number of interviewees judged to have High, Moderate, and Low informal incentives to detect errors who did and did not report detecting data errors. Notice that none of the interviewees who did not report error detection incidents reported that strong informal incentives to detect data errors exist in their organizations. In contrast, seven of the interviewees who did report error detection incidents also reported strong informal incentives to detect data errors.

\begin{tabular}{|l|l|l|l|}
\cline { 2 - 4 } \multicolumn{1}{c|}{} & \multicolumn{3}{c|}{ Informal Incentives } \\
\hline Performance & High & Moderate & Low \\
\hline Error Detected & 7 & 4 & 3 \\
\hline $\begin{array}{l}\text { Error Not } \\
\text { Detected }\end{array}$ & 0 & 2 & 4 \\
\hline
\end{tabular}

Table 4. Relationship Between Informal Incentives and Performance

Even so, a chi-square test does not support the hypothesis that there is a relationship between informal incentives and error detection at a level of significance of $.05\left(\chi_{2}{ }^{2}=5.467\right.$; $p<$ .10). Because this test is not statistically significant, an exploratory analysis was performed to determine whether the effect of a high level of informal incentives is different than the effect of moderate or low incentives. Table 5 pools the interviewees reporting moderate or low incentives to detect errors. 


\begin{tabular}{|l|l|l|}
\cline { 2 - 3 } \multicolumn{1}{c|}{} & \multicolumn{2}{l|}{ Informal Incentives } \\
\hline Performance & High & Moderate/Low \\
\hline Error Detected & 7 & 7 \\
\hline $\begin{array}{l}\text { Error Not } \\
\text { Detected }\end{array}$ & 0 & 6 \\
\hline
\end{tabular}

Table 5. Relationship Between High Levels of Informal Incentives and Performance

A chi-square test for this contingency table suggests that the effect of a high level of informal incentives on error detection performance is different than the effect of all lower levels of informal incentives to detect errors $\left(\chi_{1}^{2}=4.61 ; \mathrm{p}<.05\right)$.

\section{Materiality.}

Table 6 shows the number of interviewees judged to have High, Moderate, and Low perceptions of the materiality of data errors who did and did not report detecting data errors. Notice that none of the interviewees who did not report error detection incidents reported that errors in data are highly material to business outcomes. In contrast, eight of the interviewees who did report error detection incidents also reported that errors in data are highly material to business outcomes.

\begin{tabular}{|l|l|l|l|}
\cline { 2 - 4 } \multicolumn{1}{c|}{} & \multicolumn{3}{c|}{ Materiality } \\
\hline Performance & High & Moderate & Low \\
\hline Error Detected & 8 & 3 & 3 \\
\hline $\begin{array}{l}\text { Error Not } \\
\text { Detected }\end{array}$ & 0 & 1 & 5 \\
\hline
\end{tabular}

Table 6. Relationship Between Materiality and Performance

A chi-square test supports the hypothesis that there is a relationship between the materiality of data errors and selfreports of error detection $\left(\chi_{2}^{2}=7.50 ; \mathrm{p}<.05\right)$.

\section{Ease of Verifying Suspected Errors.}

Table 7 shows the number of interviewees judged to have High, Moderate, and Low perceptions of the ease of verifying suspected data errors who did and did not report detecting data errors. Half (three out of six) of the interviewees who did not report error detection incidents reported that the ease of verifying suspected data errors is high. This proportion is almost as high as for those interviewees who reported error detection incidents. Eight out of fourteen of the interviewees who reported error detection incidents also reported that it is easy to verify suspected data errors.

A chi-square test does not support the hypothesis that there is a relationship between the ease of verifying suspected data errors and error detection $\left(\chi_{2}^{2}=.086 ; \mathrm{p}>.10\right)$.

\begin{tabular}{|l|l|l|l|}
\cline { 2 - 4 } \multicolumn{1}{c|}{} & \multicolumn{3}{c|}{$\begin{array}{c}\text { Ease of Verifying } \\
\text { Suspected Data Errors }\end{array}$} \\
\hline Performance & High & Moderate & Low \\
\hline Error Detected & 8 & 6 & 0 \\
\hline $\begin{array}{l}\text { Error Not } \\
\text { Detected }\end{array}$ & 3 & 3 & 0 \\
\hline
\end{tabular}

Table 7. Relationship Between Verifying Suspected Data Errors and Performance

\section{Ease of Correcting Errors.}

Table 8 shows the number of interviewees judged to have High, Moderate, and Low perceptions of the ease of correcting data errors who did and did not report detecting data errors. Half (three out of six) of the interviewees who did not report error detection incidents reported that the ease of correcting data errors is high. This proportion is not quite as high as for those interviewees who did report error detection incidents. Sixty-four percent (nine out of fourteen) of the interviewees who reported error detection incidents also reported that it is easy to correct data errors.

\begin{tabular}{|l|l|l|l|}
\cline { 2 - 4 } \multicolumn{1}{c|}{} & \multicolumn{3}{c|}{$\begin{array}{c}\text { Ease of Correcting Data } \\
\text { Errors }\end{array}$} \\
\hline Performance & High & Moderate & Low \\
\hline Error Detected & 9 & 5 & 0 \\
\hline $\begin{array}{l}\text { Error Not } \\
\text { Detected }\end{array}$ & 3 & 2 & 1 \\
\hline
\end{tabular}

Table 8. Relationship Between Correcting Data Errors and Performance 
A chi-square test does not support the hypothesis that there is a relationship between the ease of verifying and correcting data errors and error detection $\left(\chi_{2}^{2}=2.48 ; \mathrm{p}>.10\right)$.

\section{Base Rate of Errors and Error Detection}

The last column of the table in Appendix B presents the estimates of the base rate of errors for the twenty interviewees. Interviewees were asked to discuss the types of reports that they use and estimate the number of these reports containing at least one serious data error. All of the base rate estimates in Appendix B refer to the percentage of these reports believed to contain at least one serious data error. Some of the interviewees provided base rate estimates for several types of reports and some of the interviewees provided a range when asked for an error rate for a particular type of report. For these interviewees, the numbers presented in Table 9 are the average base rate estimate given.

Table 9 shows the number of interviewees with High, Moderate, and Low rates of serious data errors who did and did not report detecting data errors. Because we had no $a$ priori definition of low, moderate, and high rates of errors, the twenty observations were split into three roughly equal groups. The judgment Low was assigned to the seven interviewees who gave base rate estimates less than one percent. The judgment Moderate was assigned to the six interviewees who gave base rate estimates less than or equal to five percent. The judgment High was assigned to the seven interviewees who gave base rate estimates greater than five percent.

\begin{tabular}{|l|l|l|l|}
\cline { 2 - 4 } \multicolumn{1}{c|}{} & \multicolumn{3}{c|}{ Perceived Base Rates } \\
\hline Performance & High & Moderate & Low \\
\hline Error Detected & 7 & 5 & 2 \\
\hline $\begin{array}{l}\text { Error Not } \\
\text { Detected }\end{array}$ & 0 & 1 & 5 \\
\hline
\end{tabular}

Table 9. Relationship Between Perceived Base Rates and Performance

A chi-square test supports the hypothesis that there is a relationship between the perceived base rate of errors and error detection $\left(\chi_{2}^{2}=10.60 ; \mathrm{p}<.005\right)$.

\section{Discussion of Results and Conclusion}

Table 10 summarizes the findings for each of the research propositions. Results for the field interview study as well as the prior laboratory experiments are presented.

The findings of the field interview study suggest that the materiality of data errors and expectations about the base rate of errors are related to error detection performance. Although we did not find a straight-forward relationship between different levels of incentives to detect errors and error detection performance, it appears that users who believe that strong informal incentives to detect data errors are present in their organizations are more likely to detect errors than those without this belief.

The central question posed in this paper is whether the findings of laboratory experiments on user detection of data errors are generalizable to organizational settings. The results of the study provide some support for the contention that the laboratory findings are generalizable.

First, the generalizability of the finding that base rate expectations developed through direct experience affect error detection is supported by the results of the field study. Users with perceptions of higher error rates are more likely to report incidents of error detection than users with perceptions of lower error rates. As in laboratory experiment 2, users in organizational settings typically develop expectations about the base rate of errors in data through direct experience working with data.

The generalizability of the laboratory finding that incentives affect error detection performance is less clearly supported by the field interviews. Strong formal incentives to detect data errors were simply not reported by the vast majority of the interviewees working in organizations. The lack of strong formal incentives in organizations makes it difficult to adequately test the generalizability of this laboratory finding. However, the field interviews do show that strong informal incentives are associated with incidents of error detection. This suggests that formal incentives to detect data errors might have an even stronger effect on detection performance if they were implemented in organizations. 


\begin{tabular}{|l|c|c|}
\hline \multicolumn{1}{|c|}{ Proposition } & Findings from Field Interviews & $\begin{array}{c}\text { Findings from Prior Laboratory } \\
\text { Experiments }\end{array}$ \\
\hline $\begin{array}{l}\text { P1: Formal incentives will } \\
\text { positively affect error detection } \\
\text { performance. }\end{array}$ & $\begin{array}{l}\text { Little evidence that formal } \\
\text { incentives to detect data errors } \\
\text { exist in organizations. }\end{array}$ & $\begin{array}{c}\text { Supported for cash prize } \\
\text { incentives. }\end{array}$ \\
\hline $\begin{array}{l}\text { P2: Informal incentives will } \\
\text { positively affect error detection } \\
\text { performance. }\end{array}$ & $\begin{array}{l}\text { A high level of informal incentives } \\
\text { is associated with better error } \\
\text { detection performance. }\end{array}$ & Not tested. \\
\hline $\begin{array}{l}\text { P3: Perceptions about the } \\
\text { materiality of data errors will } \\
\text { positively affect error detection } \\
\text { performance. }\end{array}$ & Supported. \\
\hline $\begin{array}{l}\text { P4: Perceptions about the ease of } \\
\text { verifying suspected data errors } \\
\text { will positively affect error } \\
\text { detection performance. }\end{array}$ & Not supported. & Supported. \\
\hline $\begin{array}{l}\text { P5: Perceptions about the ease of } \\
\text { correcting data errors will } \\
\text { positively affect error detection } \\
\text { performance. }\end{array}$ & Not supported. \\
\hline $\begin{array}{l}\text { P6: Perceptions about the base } \\
\text { rate of errors will positively } \\
\text { affect error detection performance. }\end{array}$ & $\begin{array}{l}\text { Nase rate expectations developed } \\
\text { through direct experience affect } \\
\text { error detection performance. }\end{array}$ \\
\hline
\end{tabular}

Table 10. Summary of Results

There is also additional evidence that users' assessments of the payoffs of error detection in the form of perceptions about the materiality of data errors affect error detection. Perceptions of the ease of verifying and correcting data errors did not have this effect primarily because most users believe it is easy to verify suspected data errors and correct confirmed errors.

\section{Limitations of the study.}

There are a number of limitations inherent in the methodology used in the field interview study. First, we were not able to gather objective performance measures using the interview methodology. Instead, we measured performance through selfreported data. One limitation of self-reported performance is potential biases in accounts of error detection. For example, some interviewees might have forgotten incidents in which they found errors in data.

Second, it is not possible to be certain about the directionality of relationships among the research constructs using data collected in field interviews. It is possible, for example, that the experience of detecting data errors causes users to increase their estimates of organizational incentives to detect errors, the materiality of data errors, and the base rate of errors in data. This methodological weakness is less of a limitation in this field study than would typically be the case because the causal links are clear in the complementary laboratory experiments (Klein et al., 1997, Klein, 1999).

Third, there are few subjects in some of the cells of the contingency tables used in the analysis of the field data. The findings of the study should, therefore, be confirmed in a larger scale study and in experimental research.

\section{Directions for future research.}

Additional studies addressing the detection of errors in data by users of information systems could take several paths. Two avenues will be suggested here. First, studies to develop and test prescriptive interventions to improve error detection based on the findings of the experiments and the field 


\section{Detecting Data Errors}

interviews should be conducted. Second, there is little evidence that organizations are using formal incentive systems to improve user error detection. We argue that organizational incentives linking performance evaluations, employee compensation, and formal employee recognition to important information quality objectives should be developed and tested.

\section{References}

Agmon, N., \& Ahituv, N. (1987). Assessing data reliability in an information system. Journal of Management Information Systems, 4(2), 34-44.

Ballou, D. P., \& Pazer, H. L. (1985). Modeling data and process quality in multi-input, multi-output information systems. Management Science, 31, 150-162.

Ballou, D. P., \& Pazer, H. L. (1987). Cost/quality tradeoffs for control procedures in information systems. OMEGA: International Journal of Management Science, 15, 509-521.

Ballou, D. P., \& Pazer, H. L. (1995). Designing information systems to optimize the accuracy-timeliness tradeoff. Information Systems Research, 6, 51-72.

Ballou, D. P., Pazer, H. L., Belardo, S., \& Klein, B. (1987). Implications of data quality for spreadsheet analysis. Data Base, 18(3), 13-19.

Ballou, D. P, \& Tayi, G. K. (1989). Methodology for allocating resources for data quality enhancement. Communications of the ACM, 32, 320-329.

Bansal, A., Kauffman, R. J., \& Weitz, R. R. (1993). Comparing the modeling performance of regression and neural networks as data quality varies: A business value approach. Journal of Management Information Systems, 10, 11-32.

Bowen, P. L. (1992). Managing data quality in accounting information systems: A stochastic clearing system approach. Dissertation Abstracts International, (University Microfilms No. 9319179).

Campbell, J. P. (1990). Modeling the performance prediction problem in industrial and organizational psychology. In M. D. Dunnette and L. M. Hough (Eds.), Handbook of Industrial and Organizational Psychology (2nd ed., Vol. 1, pp. 687-732). Palo Alto, CA: Consulting Psychologists Press, Inc.

Davenport, T. H. (1997). Information ecology. New York: Oxford University Press.

Davis, G. B., Neter, J., \& Palmer, R. R. (1967). An experimental study of audit confirmation. Journal of Accountancy, 123(6), 36-44.

Davis, G. B., \& Olson, M. H. (1985). Management information systems: Conceptual foundations, structure, and development. New York: McGraw-Hill Book Company.
Eisenhardt, K. M. (1989). Building theories from case study research. Academy of Management Review, 4, 532-550.

Escalle, C.X., \& Cotteleer, M.J. (1999). Enterprise resource planning (ERP). Harvard Business School Technology Note 9-699-020.

Ferdinandi, P. L. (1999). Data warehousing advice for managers. New York: American Management Association.

Flanagan, J. C. (1954). The critical incident technique. Psychological Bulletin, 51, 327-358.

Fox, C., Levitin, A., \& Redman, T. (1993). The notion of data and its quality dimensions. Information Processing \& Management, 30, 9-19.

Fromkin, H.L., \& Streufert, S. (1976). Laboratory experimentation. In M. D. Dunnette (Ed.), Handbook of Industrial and Organizational Psychology (pp. 415-465). Chicago: Rand McNally College Publishing Company.

Gaba, A., \& Winkler, R. L. (1992). Implications of errors in survey data: A Bayesian model. Management Science, 38, 913-925.

Garfinkel, R. S., Kunnathur, A. S., \& Liepins, G. E. (1986). Optimal imputation of erroneous data: Categorical data, general edits. Operations Research, 34, 744-751.

Ham, J., Losell, D., \& Smieliauskas, W. (1985). An empirical study of error characteristics in accounting populations. The Accounting Review, 60, 387-406.

Huang, K., Lee, Y.W., \& Wang, R. T. (1999). Quality information and knowledge. Upper Saddle River, New Jersey: Prentice Hall.

Huh, Y. U., Keller, F. R., Redman, T. C., \& Watkins, A. R. (1990). Data quality. Information and Software Technology, 32, 559-565.

Janson, M. (1988). Data quality: The Achilles heel of end-user computing. OMEGA: International Journal of Management Science, 16, 491-502.

Johnson, J. R., Leitch, R. A., \& Neter, J. (1981). Characteristics of errors in account receivable and inventory audits. The Accounting Review, 56, 270-293.

King, N. (1994). The qualitative research interview. In C. Cassell and G. Symon (Eds.), Qualitative Methods in Organizational Research (p. 14-36). Thousand Oaks, CA: Sage Publications.

Klein, B.D. (1997). How do actuaries use data containing errors? Models of error detection and error correction. Information Resources Management Journal, 10(4), 27-36.

Klein, B.D. (1999). Detecting errors in data: Clarification of the impact of base rate expectations and incentives. Working paper.

Klein, B.D., Goodhue, D.L., \& Davis, G.B. (1997). Can humans detect errors in data?: Impact of base rates, incentives, and goals. MIS Quarterly, 21(2), 169-194. 
Knight, B. (1992). The data pollution problem. Computerworld, 26(39), 81-83.

Laudon, K. C. (1986). Data quality and due process in large interorganizational record systems. Communications of the ACM, 29, 4-11.

Madnick, S. E., \& Wang, R. Y. (1992). Introduction to the TDQM research program. Total Data Quality Management Research Program Working Paper \#92-01.

Miles, M. B., \& Huberman, A. M. (1994). Qualitative data analysis. Thousand Oaks, CA: Sage Publications.

Morey, R. C. (1982). Estimating and improving the quality of information in a MIS. Communications of the ACM, 25, 337-342.

Naus, J. I. (1975). Data quality control and editing. New York: Marcel Dekker, Inc.

O'Leary, D. E. (1993). The impact of data accuracy on system learning. Journal of Management Information Systems, 9, 83-98.

O'Neill, E. T., \& Vizine-Goetz, D. (1988). Quality control in online databases. In M. E. Williams (Ed.), Annual Review of Information Science and Technology, (pp. 125-156). Amsterdam: Elsevier Science Publishers.

Paradice, D. B., \& Fuerst, W. L. (1991). An MIS data quality methodology based on optimal error detection. Journal of Information Systems, 5(1), 48-66.
Parsaye, K., \& Chignell, M. (1993). Data quality control with SMART databases. AI Expert, 8(5), 23-27.

Redman, T. C. (1992). Data quality: Management and technology. New York: Bantam Books.

Redman, T. C. (1995). Improve data quality for competitive advantage. Sloan Management Review, 36(2), 99-107.

Ricketts, J. A. (1990). Powers-of-ten information biases. MIS Quarterly, 14, 63-77.

Robinson, A.G., \& Dilts, D.M. (June 1999). OR \& ERP: A match for the new millennium? OR/MS Today, 30-35.

Stone, M., \& Bublitz, B. (1984). An analysis of the reliability of the FASB data bank of changing price and pension information. The Accounting Review, 59, 469-473.

Svanks, M.I. (1988). Integrity analysis. Information and Software Technology, 30, 595-605.

Wand, Y., \& Wang, R. Y. (1994). Anchoring data quality dimensions in ontological foundations. Total Data Quality Management Research Program Working Paper \#94-03.

Yin, R. (1989). Case study research. Beverly Hills, CA: Sage Publications.

Zmud, R. W. (1978). An empirical investigation of the dimensionality of the concept of information. Decision Sciences, 9, 187-195.

\section{Appendix A}

\section{Example of an Error Detection Incident}

The following error detection incident is excerpted from the transcript of an interview with a municipal bond analyst.

I just got one the other day which sent me two different reports with totally different numbers on them...The same hospital sent two reports. I don't know which is accurate...This was this hospital in New Jersey...The numbers I'm reading are the first quarter 1994 which is three months into March $31^{\text {st }}, 1994$. Now, one report they're sending me says, it's entitled key financial indicators...It lists their admission of 2344. Another report which they sent me...lists their admissions at 3077 which is 700 different. That's a significant difference. I'm like "what is going on here?" Patient days they list at 18,445 on the key indicator report and 19,406 days on the other report. Length of stay is listed 7.9 on the key indicator report and 6.3 on the other report. And this just goes on and on and on. Every one of these is different. They are completely different. And I don't know where these numbers are coming from. 


\section{Appendix B}

\section{Summary of Analysis of Interview Transcripts}

\begin{tabular}{|c|c|c|c|c|c|c|c|c|}
\hline $\begin{array}{l}\text { Interviewee } \\
\text { Number }\end{array}$ & $\begin{array}{l}\text { Professional } \\
\text { Domain }^{1}\end{array}$ & $\begin{array}{l}\text { Error } \\
\text { Detected }\end{array}$ & $\begin{array}{l}\text { Formal } \\
\text { Incentives }\end{array}$ & $\begin{array}{l}\text { Informal } \\
\text { Incentives }\end{array}$ & $\begin{array}{l}\text { Perceived } \\
\text { Materiality }\end{array}$ & $\begin{array}{l}\text { Ease of } \\
\text { Verifying } \\
\text { Errors }\end{array}$ & $\begin{array}{l}\text { Ease of } \\
\text { Correcting } \\
\text { Errors }\end{array}$ & $\begin{array}{l}\text { Base } \\
\text { Rate of } \\
\text { Errors }\end{array}$ \\
\hline 1 & CPM & Yes & Low & Low & Low & Moderate & High & $4 \%$ \\
\hline 2 & CPM & Yes & Low & Low & Low & High & High & $1 \%$ \\
\hline 3 & CPM & No & Low & Low & Low & Moderate & Moderate & $0 \%$ \\
\hline 4 & CPM & No & Low & Low & Moderate & High & High & $0.5 \%$ \\
\hline 5 & CPM & No & Low & Low & Low & Moderate & Low & $0 \%$ \\
\hline 6 & IM & No & Low & Moderate & Low & Moderate & Moderate & $0 \%$ \\
\hline 7 & IM & No & Low & Low & Low & High & High & $0.5 \%$ \\
\hline 8 & IM & Yes & Low & Low & High & High & High & $7.5 \%$ \\
\hline 9 & IM & No & Low & Moderate & Low & High & High & $2 \%$ \\
\hline 10 & IM & Yes & Low & High & High & High & High & $0.5 \%$ \\
\hline 11 & MBA & Yes & Moderate & High & High & High & High & $5.5 \%$ \\
\hline 12 & MBA & Yes & Low & High & High & Moderate & Moderate & $5.3 \%$ \\
\hline 13 & MBA & Yes & Low & Moderate & Low & High & High & $3.4 \%$ \\
\hline 14 & MBA & Yes & High & High & High & Moderate & Moderate & $0 \%$ \\
\hline 15 & MBA & Yes & Moderate & High & High & High & High & $4.8 \%$ \\
\hline 16 & $\mathrm{ACT}$ & Yes & Low & High & Moderate & Moderate & Moderate & $5 \%$ \\
\hline 17 & $\mathrm{ACT}$ & Yes & Moderate & Moderate & Moderate & High & High & $70 \%$ \\
\hline 18 & $\mathrm{ACT}$ & Yes & Low & Moderate & Moderate & Moderate & Moderate & $90 \%$ \\
\hline 19 & $\mathrm{ACT}$ & Yes & Low & Moderate & High & Moderate & Moderate & $100 \%$ \\
\hline 20 & $\mathrm{ACT}$ & Yes & Moderate & High & High & High & High & $95 \%$ \\
\hline
\end{tabular}

${ }^{1} \mathrm{CPM}=$ Consumer product management; $\mathrm{IM}=$ Inventory management; $\mathrm{MBA}=$ Municipal bond analysis; $\mathrm{ACT}=\mathrm{Actuarial}$ science . 